\title{
Téoros
}

Revue de recherche en tourisme

\section{Tourisme et musées : le mariage de raison}

\section{Marc Laplante}

Volume 11, numéro 2, juillet 1992

Quand les musées s’ouvrent au tourisme...

URI : https://id.erudit.org/iderudit/1078083ar

DOI : https://doi.org/10.7202/1078083ar

Aller au sommaire du numéro

Éditeur(s)

Université du Québec à Montréal

ISSN

0712-8657 (imprimé)

1923-2705 (numérique)

Découvrir la revue

Citer ce document

Laplante, M. (1992). Tourisme et musées : le mariage de raison. Téoros, 11(2),

2-2. https://doi.org/10.7202/1078083ar d'utilisation que vous pouvez consulter en ligne.

https://apropos.erudit.org/fr/usagers/politique-dutilisation/ 


\section{Présentation

Le comité de rédaction de Téoros a retenu le thème des relations entre tourisme et musées il y a un an, quand I"ICOM choisit de tenir à Québec son congrès mondial de 1992, quand les fêtes du 350 e anniversaire de la fondation de Montréal ont attiré l'attention sur le patrimoine d'une part et aussi sur l'ouverture, en cette année, de Pointe-àCallière, du Biôdome, du musée d'Art contemporain ainsi que la ré-ouverture du musée McCord, du musée des Beaux-Arts de Montréal, etc. La métropole comme destination culturelle et la capitale comme destination patrimoniale: décidément, le tourisme culturel risquait de faire une percée au Québec cette année et Téoros a voulu être de la partie en explorant un aspect important de ce sujet: le rôle des musées dans le tourisme et réciproquement, la place du tourisme dans la vie des musées et des lieux patrimoniaux.

Diverses études avaient dejà constaté que les livresguides touristiques ne manquaient jamais de souligner l'existence de la moindre institution muséale ou patrimoniale; le monde touristique r'ignorait donc pas les musées. Demême, quin'apas notél'intérêt croissantdes musées, d'annéeenannéepour offrir de super expositions durant la haute saison du tourisme et dans des lieux touristiques: lemonde muséal et patrimonial lex: /'histoire d'un royaume, au Saguenay) n'ignoraient donc pas le tourisme.

Bien convaincu de la pertinence du sujet, le soussigné, coordonnateur de ce numéro, a définidivers sous-thèmes et s'est mis en quête d'auteurs.

La réponse du monde muséal fut variée et souvent, révélatrice. On le constatera aisément en lisant les textes de Madame France Gascon, présidente de la Société des musées québécois, de Madame Sylvie Gagnon, directrice générale du même organisme, de Madame Marilyn Johnson du musée de la Civilisation à Québec et notre compte-rendu des entrevues avec des responsables de six grandes institutions muséales de Montréal.

Parcontre, lemonde du tourisme et notamment, celuides professionnels de l'industrie, n'a pas répondu malgré de nombreuses tentatives pour expliciter le sujet à des voyagistes, a des concepteurs de forfaits ou de circuits touristiques, à des responsables de promotion ou à des spécialistes de la visite guidée! Le beléquilibre inscritdans les textes d'orientation et le plan du futur numéro venait d'affronter la réalité: les intervenants touristiques ont semblé "désemparés" devant la question! Intégrer les institutions muséales et patrimoniales dans les opérations touristiques régulières n'est peutêtre pas la chose la plus simple, même si on n'hésite pas à les utiliser dans les livres-guides et les autres outils de promotion. Voilà donc un beau sujet à approfondir prochainement.

Le présent numéro n'a pas oublié cependant de solliciter la contribution de chercheurs: Madame Marie-Janou Lusignan a résumé ici un long travail fait dans le cadre de ses études de maîtrise en muséologie pour retracer rapidement l'histoire des relations générales entre le musée et le tourisme depuis deux siècles; Monsieur Valéry Patin, de France, présente l'influence du tourisme sur l'évolution des musées en Europe depuis deux décennies; Madame Suzanne Chassé et Monsieur JeanPaulThomin résument de récentes enquêtes québécoises et canadiennes sur les divers types de musées et leurs publics et Monsieur Jean-Claude Jay-Rayon, assisté de Madame Brigitte Morneau, font part des tendances les plus récentes dans les tentatives d'intégration du patrimoine et du tourisme.

Et notre fidèle correspondant pour l'Europe, Monsieur André Hut, de Belgique, nous propose un bilan important des tentatives européennes pour ouvrir les musées aux touristes culturels et particulièrement, auxjeunes. Quant à notre collègue et ami Pierre Mayrand, il nous rappelle, en quelques paragraphes seulement, que sa recherche prospective est toujours fructueuse: le touriste n'est jamais tout à fait celui qu'on imagine!

Bonne lecture ! f 